\title{
EDITORIAL
}

\section{Wait times: not the only indicator of performance}

Armen Aprikian, MD, FRCSC

Interim Editor-in-Chief CUAJ
W aiting an unnecessarily long time for surgery is obviously distressing, especially when one is suffering from a serious condition such as cancer. In this issue of CUAJ, Kawakami and colleagues' from Queen's University report their analysis of surgical wait times since 2003 in a group urology practice. The importance of their work lies in the real-time prospective and digitized booking system that collects various categories of information, thus making the data much more accurate and reliable as compared with several other studies in this field. The authors noticed an unfortunate steady rise in wait times over the last few years in both benign and cancer surgeries, with patients waiting a median of 56 days for cancer surgery in 2007. This, despite all the attention that wait times have received in Canada and especially in Ontario over the past several years. The authors correctly point out that government financial incentives do not always result in improved performance from a wait times perspective; other measures are often required. Furthermore, this study measures only the time between the moment that the decision was made to operate and the time of surgery. We know that before the decision to operate is made there are multiple other segments of time where patients may be waiting. We look forward to future reports from this group as their system and data set matures. In December 2005, the CUA sponsored an important consensus conference on surgical wait times in urological oncology, which resulted in a set of recommended limits on wait times for specific cancers. ${ }^{2}$ Now could be an opportune time to review the experience of Canadian urologists with respect to this indicator.

Finally, just about every province now has a website listing wait times for various hospitals and surgical procedures. Health care authorities and politicians have made surgical wait times a major indicator of performance and are encouraging the public to seek services where they are faster. Although it is highly desirable to significantly reduce wait times, this approach is of concern. Wait times are but one of several indicators that patients should be aware of, the most important being quality of care. Waiting less time for surgery at another institution does not mean that the quality of the surgery will be the same. We must ensure that quality of care, albeit more difficult to measure, remains paramount.

\section{References}

1. Kawakami J, Hopman WM, Smith-Tryon R, et al. Measurement of surgical wait times in a universal health care system. Can Urol Assoc J 2008;2: 597-603.

2. Fleshner N, Dranitsaris G, Finelli A, et al. Canadian Surgical Wait Times (SWAT) Initiative. Surgical wait times for patients with urological cancers: a survey of Canadian surgeons. Can J Urol 2006;13(Suppl 3):3-13. 